\section{Mars moon in high resolution}

The crater Stickney, on Mars's moon Phobos, is shown beautifully in this new picture acquired by the HiRISE high-resolution imaging instrument aboard the Mars

Reconnaissance Orbiter.

The bluish (false) colour in this image could represent material younger than the rest of the moon's surface. Stickney, named after the wife of Phobos's discoverer, was probably formed in a giant impact that nearly shattered the moon. The crater is 9 kilometres across, the moon itself just 22 kilometres.

The long grooves that radiate out from Stickney may be left over from the impact that created it, or could have been formed by debris from the impact of another body on Mars itself, which is less than 6,000 kilometres from the moon.

of Congress, which mandated the position last September.

Frank Torti, a clinician and molecular oncologist who chairs the department of cancer biology at Wake Forest University in Winston-Salem, North Carolina, will begin the job next month. He will also serve as principal deputy commissioner, effectively the agency's second-in-command.

An expert on prostate and bladder cancer

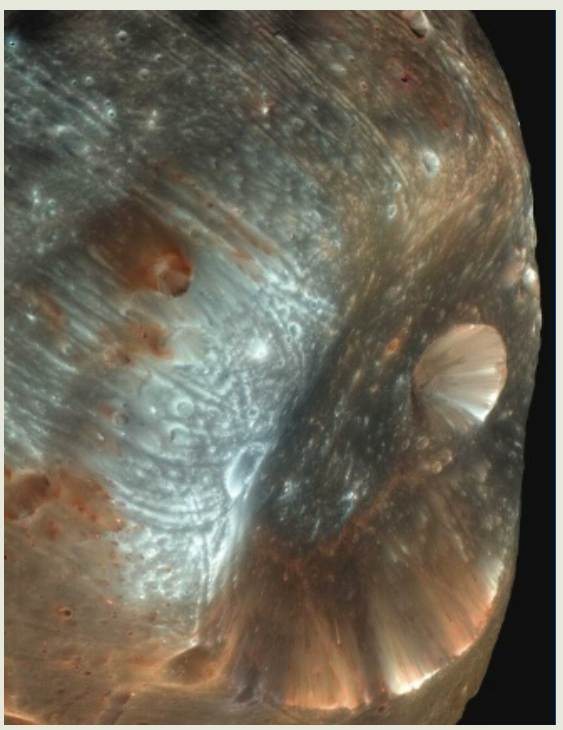

who has run many clinical trials, Torti will be charged with ensuring the quality of the agency's intramural research in response to a recent dire assessment of its scientific capabilities (see Nature 450, 1143; 2007). He will also launch a high-profile, twoyear FDA fellowship programme aimed at recruiting, training and retaining scientists and administrators in an effort to combat attrition at the agency.

\section{Indian journals push for clinical-trial registration}

Eleven of India's leading medical journals will now consider publishing the results of clinical trials only if the trial in question has been registered with the Indian Council of Medical Research (ICMR) in New Delhi or any primary clinical-trial register.

The move follows the 2005 decision by the International Committee of Medical Journal Editors to publish only the results of registered trials. According to Kanikaram Satyanarayana, deputy chief of the ICMR, the delay was partly due to reluctance by the journal editors and pressure from industry. In addition, the ICMR had hoped that a bill it drafted in 2006 to regulate human trials would become law.

Trials that start in or after June of this year must be registered before enrolling their first participant; those beginning before this must register retrospectively. The ICMR says mandatory registration will ensure transparency and honesty, and discourage unethical trials.

An estimated 250 drug trials are under way in India, with applications for $\mathbf{3 0}$ more received on average each month. 